\title{
Objective assessment of cough suppressants under clinical conditions using a tape recorder system
}

\author{
C. R: WOOLF ANDA. ROSENBERG \\ From the Respiratory Unit, Sunnybrook Hospital (Department of Veterans Affairs), and the Department \\ of Medicine, University of Toronto, Ontario, Canada
}

The primary function of a cough suppressant should be to reduce significantly the number of times a person coughs. There are two principal methods of assessing this effect. One method uses patients with pathological cough, and its conclusions are based on subjective impressions (Cass and Frederik, 1953 ; Woolf and Rosenberg, 1962). The other method uses subjects with induced cough, and conclusions are based on objective cough counts (Bickerman and Barach, 1954). The purpose of this paper is to describe a technique which employs the objectivity of cough counting to determine the effect of suppressants on pathological cough. Levo-propoxyphene (CT 1302), ${ }^{1}$ elixir of terpin hydrate with heroin, and syrup of codeine have been assessed by this technique.

\section{TECHNIQUE}

A hospital room with its own bathroom was used. The room was not sound-proofed, but rubber stripping was placed around the door to the corridor. A microphone above the head of the bed (Fig. 1) was connected through the wall to a tape recorder set at the

\footnotetext{
1 Eli Lilly and Co.
}

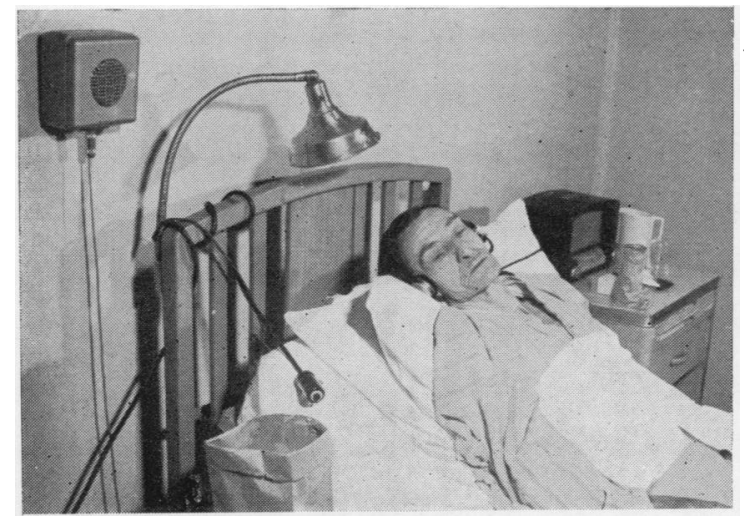

FIG. 1. Microphone in position above the head of the bed.
' on' position (Fig. 2). The recording input was connected to the microphone in the room and to a device which produced a time signal once every hour. The recorder was controlled by an electronic on/off unit which triggered the recorder into action only when a signal was received from the microphone or from the time signal sender. When the sound stopped the recorder continued to run for five seconds and then stopped. By this means it was possible to record up to 24 hours of observations on two hours of tape. The time signal sender consisted of a tape playback unit and an automatic switching arrangement activated once every hour by an electric clock. The playback unit contained an endless tape which, on activation, announced the hour by means of a pre-recorded voice. As an additional check on the time an ordinary chiming clock was added to the system and this registered both the hours and half-hours. The recordings were played back on a third tape recorder, and the coughs were counted on a hand tally counter. The sound of the cough is clearly distinguishable from all other sounds that occur throughout the day and night in the patient's room. Counts made by two independent observers during 150 hours of coughing from five different patients revealed no significant observer error (Fig. 3).

\section{METHOD}

A patient with chronic cough was placed in the room where he spent four days from Monday afternoon to Friday afternoon. He knew in advance that all sounds in his room would be recorded but he was unaware that a cough suppressant was being tested. He was told, and seemed to accept, that we were investigating the influence of peace and quiet on chest disease and that the recording system would monitor the noise level in his room. He was encouraged to behave as usual. It was decided not to interfere with his normal smoking habits. If smoking had been stopped, one would have been uncertain whether changes in cough were related to alteration in cigarette consumption or to the effects of the medication. The number of cigarettes per day was not counted as it is difficult to do so without unduly influencing the fairly constant daily cigarette consumption of the regular smoker. The patient was supplied 


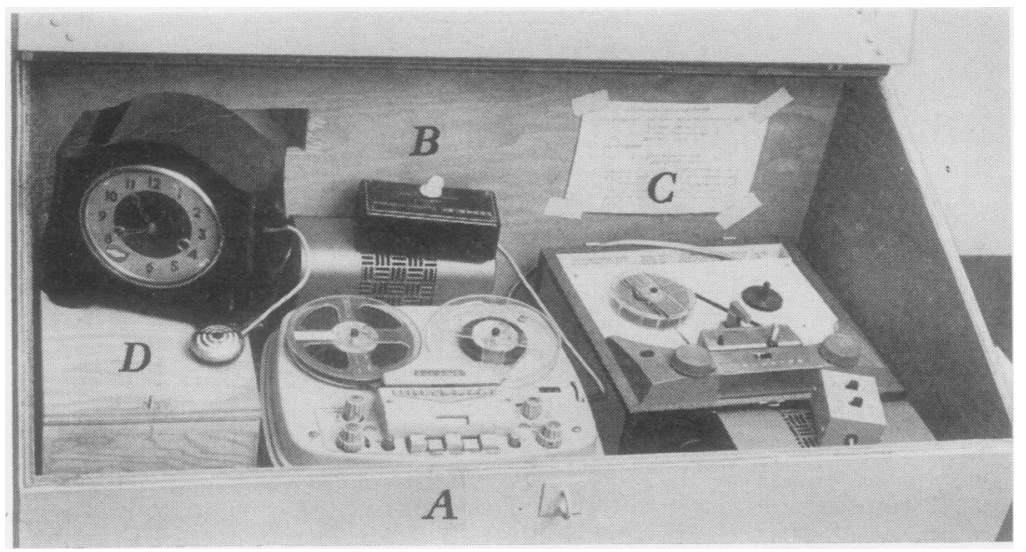

FIG. 2. Tape recorder system : $A$, ळ main tape recorder; $B$, electronic $\vec{\circ}$ on/off unit; $C$, playback unit with pre-recorded voice; $D$, chiming $\vec{\omega}$ clock with microphone.

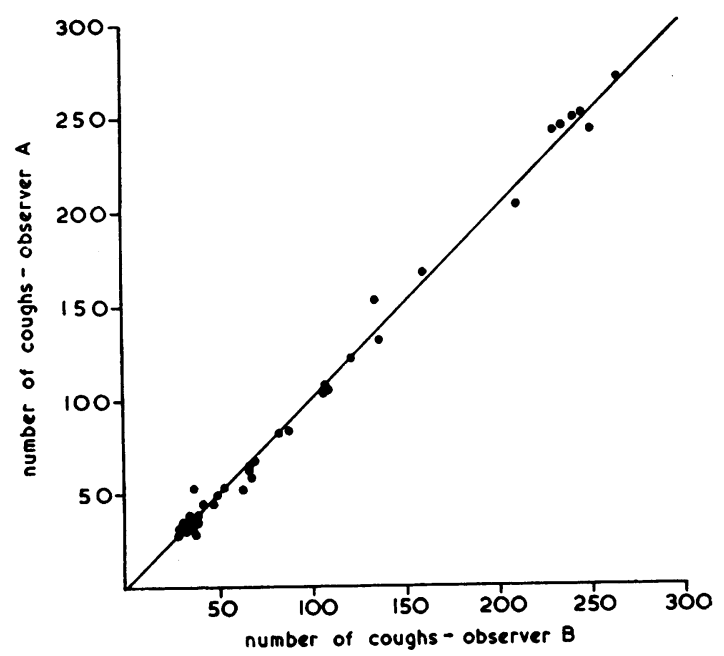

FIG. 3. Comparison of cough counts by two independent observers. Thirty-six comparisons where the number of coughs per hour was greater than 30 but less than 300 .

with reading matter and a radio with earphones (Fig. 1). Finally he was told that during the last three days in the room he would be given some medicine that might or might not help his chest trouble.

On the first day, which served as a control day, the patient received no cough medicine. On the second and third days he received a preparation which resembled but did not contain the test drug. On the fourth and final day he received the test drug.

In the assessment of levo-propoxyphene recording was started at 6 p.m. each day and continued until 5 p.m. on the following day. In the assessment of elixir of terpin hydrate with heroin and of syrup of codeine recording was started at 6 p.m. each day and continued until 4 p.m. on the following day. Recording was discontinued each day during visiting hours ( 7 p.m. to 8.30 p.m.) when the microphone was removed from the room.
In order to compare the objective evidence of the $\overrightarrow{-}$ tape recorder with the patient's subjective assessment of the treatment, a questionnaire was completed at $\overline{\widehat{\sigma}}$ 5 p.m. each day. Among a number of irrelevant ques- $\supset$ tions about breathing and sleeping were several $\overrightarrow{0}$ questions relating to cough.

\section{MATERIAL}

Three antitussive drugs were investigated. They were made up in standard dosages (see below) and $\stackrel{2}{\circ}$ given five times in 24 hours at 6 p.m., 10 p.m., 6 a.m., 10 a.m., and 1 p.m. If a cough suppressant really $\overrightarrow{\vec{D}}$ reduces cough, its effect ought to be evident after even $\frac{0}{3}$ one standard dose, and its effect should certainly be obvious if five doses are given in 24 hours.

LEVO-PROPOXYPHENE On the first day the patient received no cough medicine. On the second and third days he received a placebo capsule identical in $\times$ appearance with the test drug. On the final day he $\frac{0}{3}$ received the test drug in the manufacturer's recommended dosage of one $100 \mathrm{mg}$. capsule. The dosage was given five times in 24 hours.

ELIXIR OF TERPIN HYDRATE WITH HEROIN On the first day the patient received no cough medicine. On the second and third days he received elixir of terpin hydrate alone (each dose $60 \mathrm{minims}$ ). On the finalus day elixir of terpin hydrate with heroin $(1 / 24 \mathrm{gr}$.) was given. Medication was given five times in 24 hours.

SYRUP OF CODEINE On the first day the patient received no cough medicine. On the second and third dayso he received a syrup which resembled syrup of codeine $\overparen{D}$ in all respects (each dose 120 minims). On the final day syrup of codeine ( $\frac{1}{2}$ gr.) was given. Medication 7 was given five times in 24 hours.

Thirty male in-patients took part in the investiga-疋 tion. Ten received levo-propoxyphene, 10 received $\frac{\text { P }}{\mathbb{D}}$ elixir of terpin hydrate and heroin, and 10 syrup of codeine. The ages and diagnoses in the three groups are shown in Table I. All patients had had chronic 
TABLE I

AGE AND DIAGNOSIS

\begin{tabular}{|c|c|c|c|}
\hline & $\begin{array}{l}\text { Levo-pro- } \\
\text { poxyphene }\end{array}$ & Heroin & Codeine \\
\hline Age (yr.) $\begin{array}{l}\text { Mean } \\
\text { Range }\end{array}$ & $\begin{array}{c}66 \\
60-77\end{array}$ & $\begin{array}{l}54 \\
38-65\end{array}$ & $\stackrel{64}{52-70}$ \\
\hline $\begin{array}{l}\text { Diagnosis (No. of patients) } \\
\text { Emphysema } \\
\text { Pulmonary fibrosis } \\
\text { Chronic bronchitis } \\
\text { Bronchiectasis } \\
\text { Bronchogenic carcinoma }\end{array}$ & $\begin{array}{l}5 \\
1 \\
2 \\
2 \\
0\end{array}$ & $\begin{array}{l}6 \\
1 \\
2 \\
0 \\
1\end{array}$ & $\begin{array}{l}9 \\
0 \\
1 \\
0 \\
0\end{array}$ \\
\hline Total & 10 & 10 & 10 \\
\hline
\end{tabular}

cough for many years and were free of active infection. All cough suppressants were discontinued at least 24 hours before the patient entered the room.

\section{RESULTS}

Daily cough curves were constructed for each patient by progressively adding the number of coughs recorded every hour. Examples of such curves are shown in Figs. 4, 5, and 6. The total daily cough counts were subjected to an analysis of variance, comparisons being made between the control day, the two placebo days, and the drug day. The number of coughs recorded from 10 p.m. to midnight, 6 a.m. to 8 a.m., 10 a.m. to noon, and 1 p.m. to 3 p.m. (two hours after each dose of medication) were similarly analysed for the four days. The total daily cough counts of each patient were further analysed on the basis of percentage change, a change of more than $15 \%$ being arbitrarily considered significant.

LEVO-PROPOXYPHENE Statistical analysis of both the total daily cough counts and the two-hour post-treatment counts showed no significant differences between the control day, the two placebo days, and the drug day (Tables II and III). It was concluded that levo-propoxyphene had no significant antitussive effect.

ELIXIR OF TERPIN HYDRATE WITH HEROIN Statistical analysis of both the total daily cough counts and the two-hour post-treatment counts showed a significant reduction in cough when heroin was added to elixir of terpin hydrate. There were no significant differences between the control day and the two elixir of terpin hydrate days (Tables II and III). It was concluded that elixir of terpin hydrate with heroin is an effective cough suppressant.

SYRUP OF CODEINE Statistical analysis of both the total daily cough counts and the two-hour posttreatment counts showed significant reductions in cough when codeine was added to the syrup.
FIG. 4. Daily cough curves constructed by progressively adding the number of coughs recorded each hour. Patient W.G. Test drug levo-propoxyphene. Each drug dose is indicated by an arrow on the base line.

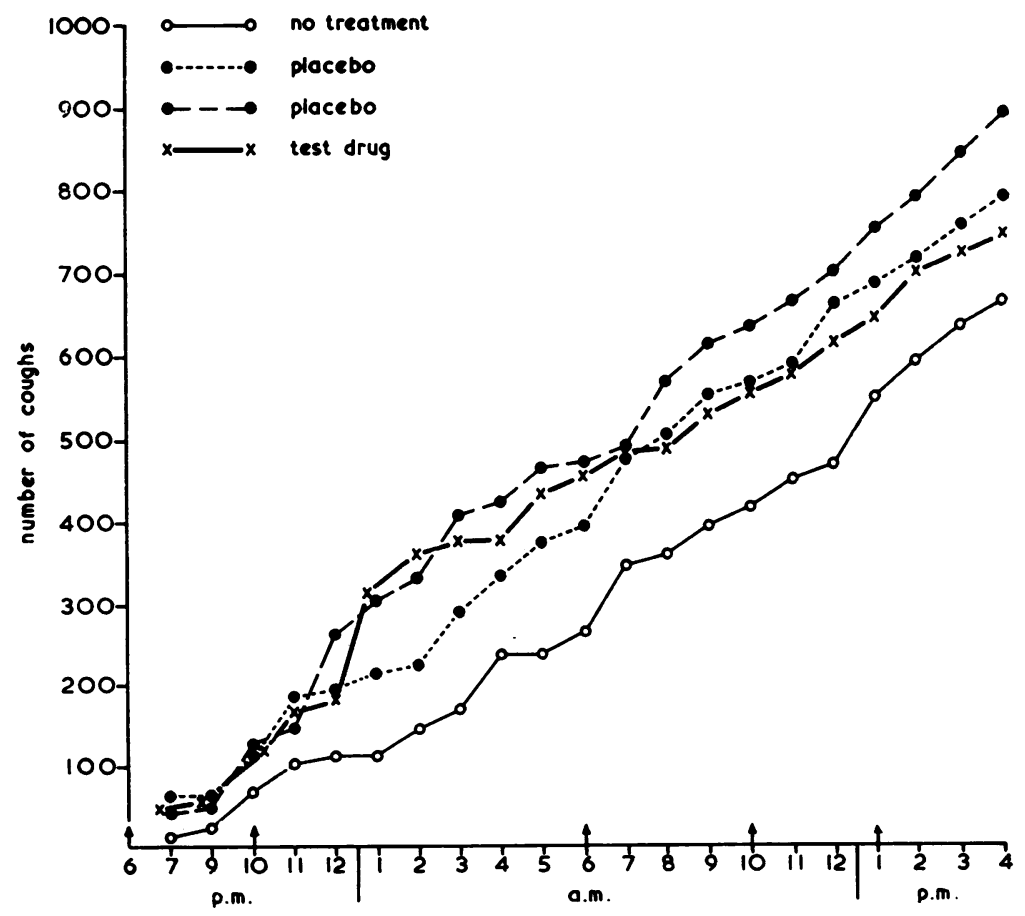




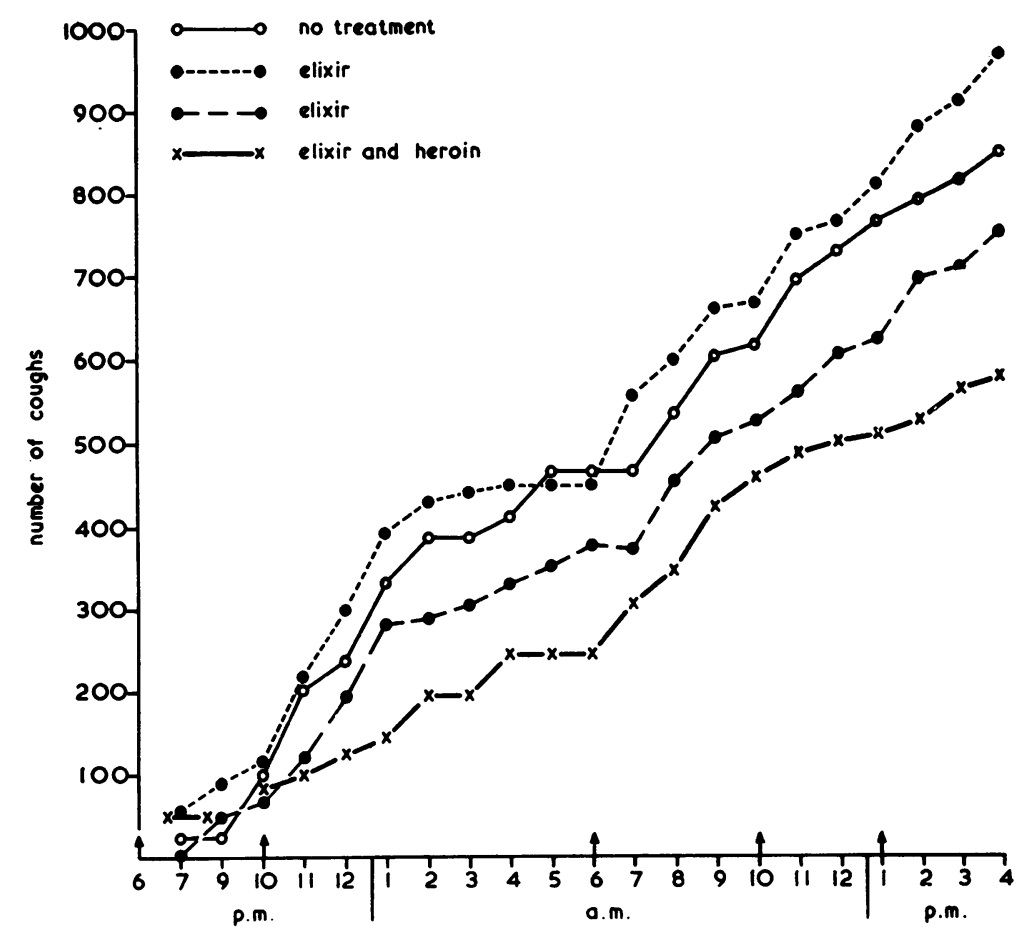

FIG. 5. Cough curves. Patient F.G.

Test drug heroin.

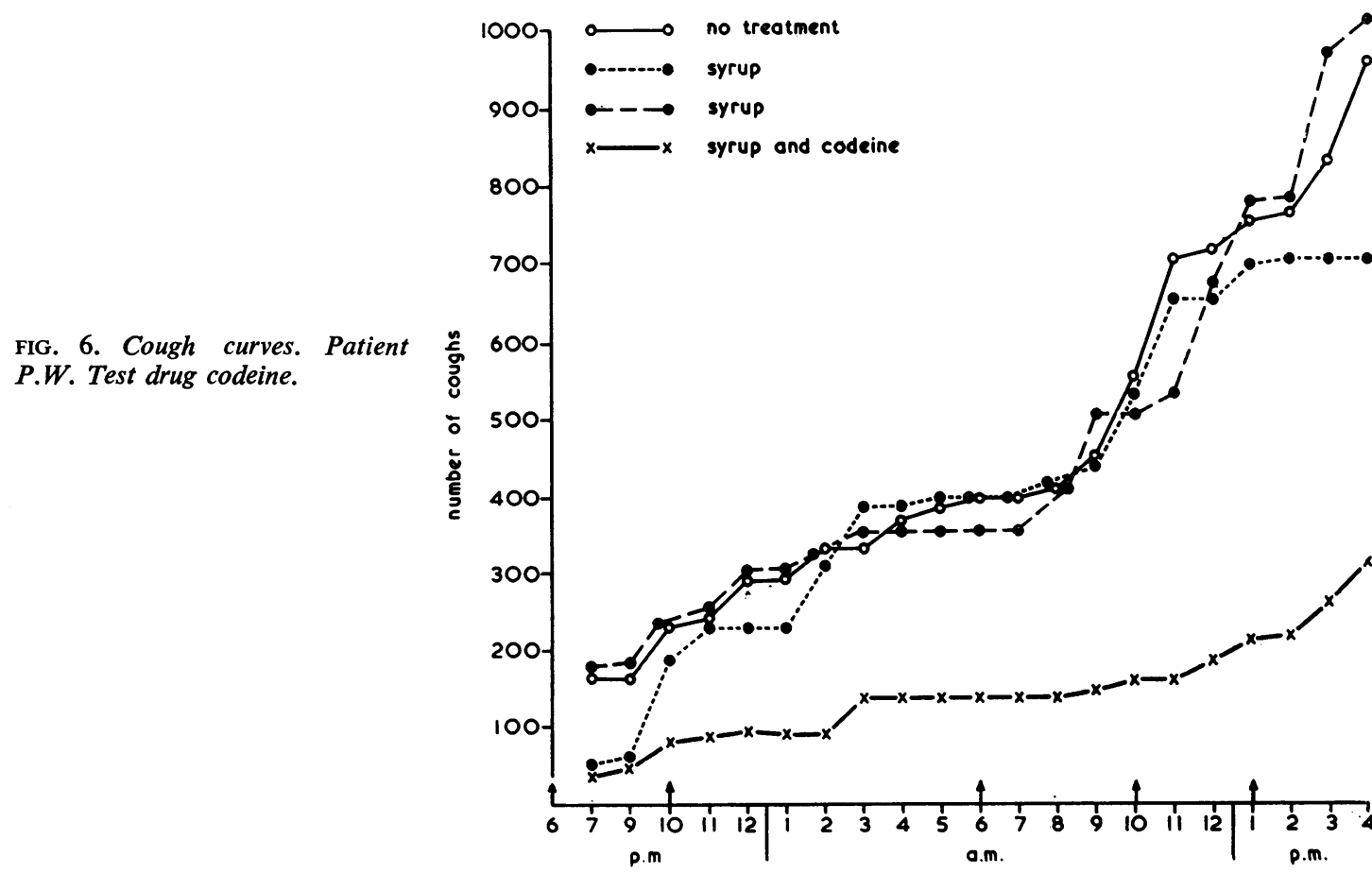


TABLE II

COUGH COUNT ANALYSIS

\begin{tabular}{l|c|c}
\hline & $\begin{array}{c}\text { Average No. } \\
\text { of Total } \\
\text { Daily Coughs }\end{array}$ & $\begin{array}{c}\text { Average No. } \\
\text { of 2-Hour } \\
\text { Post-treatment } \\
\text { Coughs }\end{array}$ \\
\hline Control day & 628 & 47 \\
Placebo & 700 & 57 \\
Levo-propoxyphene & 686 & 57 \\
\hline Control day & 761 & 61 \\
Elixir of terpin hydrate & 765 & 74 \\
Elixir of terpin hydrate with heroin & 579 & 38 \\
\hline Control day & 640 & 56 \\
Simple syrup & 513 & 51 \\
Simple syrup with codeine & 359 & 27 \\
\hline
\end{tabular}

TABLE III

STATISTICAL ANALYSIS OF COUGH COUNT DATA

\begin{tabular}{l|c|c}
\hline \multicolumn{1}{c|}{ Comparison } & \multicolumn{2}{|c}{ Level of Significance } \\
\cline { 2 - 3 } & Total Coughs & $\begin{array}{c}\text { Two-hour } \\
\text { Coughs }\end{array}$ \\
\cline { 2 - 3 } Placebo and control & N.S.D. & N.S.D. \\
Levo-propoxyphene and control & N.S.D. & N.S.D. \\
Levo-propoxyphene and placebo & N.S.D. & N.S.D. \\
\hline Elixir and control & N.S.D. & N.S.D. \\
Elixir + heroin and control & $5 \% \%$ & $0.5 \%$ \\
Elixir + heroin and elixir & $1 \%$ & $0.1 \%$ \\
\hline Syrup and control & N.S.D. & N.S.D. \\
Syrup + codeine and control & $0.5 \%$ & $0.5 \%$ \\
Syrup + codeine and syrup & $5 \%$ & $0.5 \%$ \\
\hline
\end{tabular}

N.S.D. = No significant difference

There were no significant differences between the control day and the two simple syrup days (Tables II and III). It was concluded that syrup of codeine is an effective cough suppressant.

\section{DISCUSSION}

The first drug to be assessed by the tape recorder technique was levo-propoxyphene. Although this had given evidence of a cough suppressant effect in both citric acid aerosol and clinical trials (Gruber and Carter, 1961 ; Calesnick, Christensen, and Munch, 1961), a recent publication suggested that more objective studies were required (The Medical Letter on Drugs and Therapeutics, 1962). Using the tape recorder system we have been unable to demonstrate the effectiveness of this drug. Since the citric acid aerosol technique and the tape recorder technique both base their conclusions on objective cough counts, the discrepancy in the results might be due to the possibility that cough induced by irritating agents and pathological cough respond differently to the action of some suppressants. The failure of the tape recorder to confirm the results of clinical trials is probably due to the difference in technique.
The next drug to be assessed was elixir of terpin hydrate with heroin. Previous double-blind studies by Woolf and Rosenberg (1962) had suggested that heroin had little cough suppressant effect in the dosage used and that elixir of terpin hydrate alone was the effective element in the preparation. The tape recorder technique reversed these conclusions. It is now concluded that heroin, in the same dosage as previously, is significantly effective in suppressing cough and that elixir of terpin hydrate alone is of little value. The discrepancy between the results of the double-blind studies and the tape recorder technique is in all probability due to the small number of patients used in the double-blind trial. Most patients do not accurately appreciate the day-to-day variation of their cough (see below), and clinical studies ought to deal with very large numbers of patients to overcome the unreliability of personal opinion. An advantage of the tape recorder technique is that it is possible to base conclusions on the results of a relatively small number of patients.

The third drug to be assessed was syrup of codeine. The tape recorder results supported the evidence of other investigations that codeine is an effective cough suppressant.

By recording the number of coughs each day it was possible to compare the patient's opinion as to whether his cough had changed with the objective evidence of the recorder. It was arbitrarily decided that a $15 \%$ change in the daily cough count would be large enough to make the patient aware of an increase or a decrease in his cough as compared with the previous day. Ninety comparisons were made between change in the cough count and the statements of the patients. The patient's assessment agreed with the cough count in only 39 instances. These agreements were evenly distributed over the three series, there being 13 agreements out of 30 comparisons for each of the levo-propoxyphene, elixir of terpin hydrate with heroin, and syrup of codeine groups. It was then considered that a $15 \%$ change in the daily cough count might not be sufficient for the patient to notice, and the comparisons were therefore made again, but this time on the basis of a $50 \%$ change in the cough count. The patient's assessment agreed with the recorder in only 36 of the 90 comparisons. It may be concluded that the majority of patients do not appreciate the extent to which their cough varies from day to day and that they are frequently unaware of the effects of antitussive preparations.

Just as the double-blind trial has to contend with random impressions so must the recorder technique overcome the 'normal' fluctuations of 
cough from day to day. Using the present technique, it has been possible to show that some medications reduce cough significantly in a group of patients. It is much more difficult to demonstrate the effect of a drug on an individual patient. It has not been possible to assess the individual patient in the present investigation as the day-today variation is too great to allow statistical analysis if only three control or placebo days are used. It would probably be necessary to follow the daily fluctuation of untreated cough for at least 10 days to be reasonably sure that any reduction in cough on the final drug day or days is due to the effect of the drug and does not represent some chance variation in the state of the cough.

There are no figures available as to how frequently the patient must cough to be classified as having a chronic cough. In the present series the average number of daily coughs varied from 628 to $\mathbf{7 6 1}$ for the control days. No patient had a daily cough count of less than 233 coughs, and the highest count was 2,663.

The recorder technique has proved useful in examining placebo effect. A true placebo was used only in the levo-propoxyphene series. There were seven claims of improvement after a placebo day, but in only two of these instances was there a greater than $15 \%$ reduction in cough. These findings suggest that placebos may influence the patient's attitude towards his cough without producing a real reduction in cough.

Gravenstein, Devloo, and Beecher (1954) assessed the antitussive effect of heroin and codeine by objective cough counting. A direct writing system was used to record all sounds in the patient's room. The technique was found to be 'tedious' as one of the investigators was obliged to sit outside the room and personally note which sounds were coughs. These workers posed the question: Do opiates really reduce the number of coughs or do they merely make the patient less aware of his cough ? They were unable to demonstrate that opiates produced a reduction in cough. In our series there was clearly a significant reduction in the number of coughs when heroin or codeine was administered. The way in which opiates produce this effect is not known, but a sedative action may play a part. Levopropoxyphene was perhaps ineffective simply because it lacked this sedative effect, and it may well be that no non-addicting preparation will be as effective as the opiates.

The tape recorder system supplies data for statistical analysis using only a small number of patients and is useful in the objective assessment of cough suppressants under clinical conditions.

\section{SUMMARY}

An objective method of assessing cough suppressants under clinical conditions by a tape recorder system is described. The technique is based on the principal of counting continuously recorded cough. Levo-propoxyphene, elixir of terpin hydrate with heroin, and syrup of codeine were the three drugs assessed. Thirty male inpatients with chronic cough took part in the investigation. It was shown that levo-propoxyphene produced no significant reduction in cough and that both elixir of terpin hydrate with heroin and syrup of codeine were effective cough suppressants. In spite of claims of subjective improvement, no real reduction in cough occurred after the use of a placebo. A comparison was made between the objective evidence of the recorder and the subjective observations of the patient. It was shown that patients are largely unaware of considerable changes in the state of their cough and that clinical trials which base their conclusions on subjective impressions are open to criticism on this account. The tape recorder system provides a practical means of assessing cough suppressants objectively under clinical conditions.

We wish to thank the following: Mr. S. Bacso, Respiratory Unit technician. Sunnybrook Hospital, without whose enthusiasm this investigation would not have been possible; Mr. R. Tompson, Head Pharmacist, Sunnybrook Hospital, who prepared the mixtures ; Tele-Tech Electronics Ltd., 1947 Avenue Road, Toronto 12, who designed the tape recorder system. The work was supported by Department of Veterans Affairs Research Grant 27-57 and by a grant from Eli Lilly and Company.

\section{REFERENCES}

Bickerman, H. A., and Barach, A. L. (1954). The experimental production of cough in human subjects induced by citric acid aerosols. Preliminary studies on the evaluation of antitussive agents. Amer. J. med. Sci., 228, 156.

Calesnick, B.. Christensen, J. A., and Munch, J. C. (1961). Antitussive $\omega$ action of $L$-propoxyphene in citric acid-induced cough response. $\sigma$ Ibid., 242, 560.

Cass, L. J., and Frederik, W. S. (1953). Evaluation of a new antitussive agent. New Engl. J. Med., 249, 132 . K. (1954). Effect of $\frac{C}{(}$

Gravenstein. J. S., Devloo, R. A., and Beecher, H. K. (19S4). Effect of antitussive agents on experimen
man. J. appl. Physiol. $7,119$.

Gruber, C. M. Jr., and Carter, C. H. (1961). A measure of the effec- $\square$ tiveness of propoxyphene antitussives in children. Amer. J. med. Sci.. 242, 443.

The Medical Letter on Drugs and Therapeutics (1962). 4, 77 [No. 20]. ד্ষ

(Amer. ed.)
Woolf, C. R., and Rosenberg, A. (1962). The cough suppressant effect of heroin and codeine: A controlled clinical study. Canad. med. Ass. J., 86, 810. 